\title{
Educar na era digital: considerações sobre tecnologia, conexões e educação a distância ${ }^{1}$
}

Thiago Tavares das Neves

Pós-doutor em Comunicação e Consumo pelo PPGCOM da ESPM. Doutor pelo Programa de Pós-Graduação em Ciências Sociais da UFRN. Pesquisador do Grupo Juvenália questões estéticas, geracionais, raciais e de gênero na comunicação e no consumo.

E-mail: nevesthiago1@hotmail.com

Elizama das Chagas Lemos

Doutora em Tecnologias e Sistemas de Informação pela Universidade do Minho (2019), mestre em Sistemas e Computação pela UFRN (2011).

E-mail: elizamalemos@gmail.com

Resumo: O objetivo deste artigo é problematizar a técnica, a tecnologia e as conexões com o intuito de refletir sobre a importância desses três tópicos na construção de uma aposta de aprendizado diferenciado, a educação a distância. A EAD consiste em uma modalidade de ensino e aprendizagem mediada por tecnologias e que se encontra em fase de consolidação no Brasil. Sua principal diferença reside no seu suporte (dispositivos digitais) e as conexões tecnológicas que possibilitam a mediação. É nesse contexto que a EAD entra como uma modalidade de ensino com variados recursos digitais e interativos (ambientes virtuais de aprendizagem e objetos de aprendizagem), contribuindo, dessa forma, com outros olhares no processo educativo da sociedade tecnológica.

Palavras-chave: tecnologias educacionais; conexão; educação a distância; ambientes virtuais de aprendizagem; objetos de aprendizagem.
Abstract: This article questions the technique, technology and connections in order to reflect on the importance of these three topics mentioned in the construction of a differentiated learning bet, distance education. Distance learning is a technology-mediated teaching and learning modality that is being consolidated in Brazil. Its main difference lies in its support (digital devices) and the technological connections that enable mediation. It serves as a modality of teaching with varied digital and interactive resources (virtual learning environments and learning objects), thus contributing with other perspectives in the educational process of technological society.

Keywords: educational technologies; connection; distance learning; virtual learning environments; learning objects.
1. Versão revisada e modificada de artigo apresentado na Intercom 2017.

Recebido: 01/06/2019

Aprovado: 27/09/2019 


\section{QUANDO A TÉCNICA SE TRANSFORMA EM TECNOLOGIA...}

A realidade humana (social, cultural, biológica) é atravessada pela técnica desde os tempos pré-históricos; não se pode pensar que a técnica é algo novo ou nasceu junto com as tecnologias. Engano. A técnica é arcaica, fundadora, primeira, constituinte do ser e das coisas. Tanto a cultura quanto a sociedade são fundadas sob a mediação da técnica.

De acordo com sua etimologia, a palavra deriva do grego "technê" e significa arte, artifício, produção. Para os antigos gregos, a técnica estava muito ligada à produção, modos de produzir que visam um novo sentido ou uso. A história da técnica está atravessada por uma vontade de poder que se manifesta em múltiplas formas, não apenas na violência, mas também na exploração e na aventura, na produção que constrói um mundo novo, no cuidado protetor e na ocupação do espaço. Essa vontade de poder é primitiva e se manifesta na rebeldia e na transgressão. Os limites do corpo são superados, a necessidade de sobrevivência, de domínio da técnica para poder alimentar-se e viver. O domínio do fogo pode ser um dos exemplos. Da vontade de dominar a natureza para poder existir, surge também a comunicação com a natureza. Há comunhão com o natural. Essa comunhão manifesta-se de diferentes formas, no marinheiro que se lança ao mar com o objetivo de explorar novas terras, impulso que adquire nos tempos atuais formas novas e grandiosas, com o domínio do ar e do espaço, do meio submarino, tudo isso possibilitado pelos avanços técnicos ${ }^{2}$.

É preciso enxergar na técnica moderna seu potencial libertário, sua potência criadora. Não adianta mais encará-la como um Leviatã que domina os homens ou que aliena a humanidade. Os herdeiros do pensamento da Escola de Frankfurt e toda a crítica fomentada contra a indústria compartilham um pouco dessa visão apocalíptica sobre a técnica moderna e o aparecimento dos meios de comunicação de massa, consequência do desenvolvimento técnico e tecnológico da época. Essa visão dos intelectuais alemães que pensam a técnica moderna como uma força negativa em si mesma precisa ser combatida.

A técnica é liberdade. Mas em qual sentido? A técnica é a possibilidade de manipular as causas de maneira que elas tenham as consequências que o homem queira. Por exemplo, as leis da dinâmica dos gases; com base nelas, é possível construir uma caldeira que move locomotivas. A própria técnica é também uma consequência do desenvolvimento científico. A técnica liberta no momento em que ela é o conhecimento da necessidade ${ }^{3}$. Por meio desse conhecimento, o ser humano adquire poder, sua potência é aumentada e ele domina o meio, a natureza é transformada/tecnificada/culturalizada, e numa relação recursiva e dialógica o homem também é naturalizado. A técnica abre possibilidades de criação e produção, é libertária.

Falar em técnica, principalmente na cultura contemporânea, remete a outro tema indispensável para entender as engrenagens da sociedade atual: a tecnologia. A tecnologia é consequência do desenvolvimento da técnica.

2. PARÍS, Carlos. O animal cultural: biologia e cultura na realidade humana. São Carlos: EdUFSCar, 2002.

3. FLUSSER, Vilém. Comunicologia: reflexões sobre o futuro. São Paulo: Martins Fontes, 2014 
4. Ver verbete Tecnología em: BARFIELD, Thomas (ed.). Diccionario de antropologia. Barcelona: Bellaterra, 2001.

5. FLUSSER, Vilém. O mundo codificado: por uma filosofia do design e da comunicação. São Paulo: Cosac Naify, 2007.

6. MCLUHAN, Marshall. Os meios de comunicação como extensões do homem. São Paulo: Cultrix, 2007.

7. TURKLE, Sherry. Alone together: why we expect more from technology and less from each other. Nova York: Basic Books, 2011.
É a "arte, ciência da técnica", o estudo das técnicas, instrumentos, máquinas. Meios e recursos com que as sociedades humanas fazem frente ao seu entorno material e o transformam. Nesse sentido, a tecnologia pode ser compreendida como uma junção formada por aptidões humanas, máquinas operatórias e estruturas materiais.

De acordo com Glick ${ }^{4}$, na medida em que os antropólogos têm reconhecido o homo faber como arquétipo social e destacado a utilização de ferramentas como um dos conjuntos dos artefatos culturais, a tecnologia não deixou de estar presente no repertório antropológico. Os indivíduos selecionam inconscientemente a ferramenta mais apropriada para uma tarefa específica, modificando assim gradativamente o artefato até que a forma corresponda de maneira ótima a sua função. Têm sido muitos os intentos de caracterizar os períodos históricos por critérios tecnológicos.

Flusser $^{5}$, por exemplo, classificou a história da humanidade como uma história da fabricação, e o homo faber como aquela espécie antropoide que fabrica algo. Eis os períodos históricos: o das mãos, o das ferramentas, o das máquinas e o dos aparelhos eletrônicos. Eis o processo de transformação da natureza pelo homem; esses quatro movimentos de transformação - apropriação, conversão, aplicação e utilização - são realizados primeiramente pelas mãos, depois por ferramentas, em seguida pelas máquinas e, por último, pelos aparatos eletrônicos. A fábrica do futuro irá reconfigurar a relação homem-ferramenta. A arquitetura humana irá dar lugar à arquitetura das máquinas.

Atualmente é impensável para a sociedade urbana viver sem tecnologia; a dependência dos aparelhos técnicos só aumenta com o tempo. O ser humano precisa estar conectado a algum objeto tecnológico. Os celulares inteligentes, conhecidos como smartphones, viraram uma extensão do "eu”. Marshall McLuhan ${ }^{6}$ já profetizava quando disse que os meios de comunicação são extensões do corpo humano.

De acordo com Sherry Turkle ${ }^{7}$, os computadores, por exemplo, estão mudando e afetando a vida das pessoas. O ser humano é afetado pelas ferramentas que constrói, pelas suas criações; a tecnologia afeta o indivíduo em sua completude. Há uma reconstrução do "eu" e das relações humanas através da intimidade que é criada com as máquinas. Isso acaba por gerar uma humanização das máquinas e uma maquinação do humano, pois os homens passam a dar qualidades humanas aos objetos e a tratar os outros como coisas.

Talvez o ser humano esteja se tornado de fato cyborg, a máquina se tornou parte do corpo. É vital. Os indivíduos estão cada vez mais conectados à internet, aos dispositivos digitais. Estar on-line passou a ser uma premissa para existência. Ficar off-line é o mesmo que estar morto, não existir, invisibilidade social. As pessoas amam as tecnologias da conexão; elas têm feito pais e filhos se sentirem mais seguros, sem contar a revolução que gerou nos setores de negócios, educação, medicina e dos relacionamentos amorosos. A conectividade oferece novas possibilidades de experimentar novas identidades e, particularmente na adolescência, o senso de espaço livre. 


\section{2. ... SURGEM AS CONEXÕES NA SOCIEDADE TELEMÁTICA...}

Ao caminhar nessa direção da técnica e da tecnologia se faz necessário discutir o conceito de conexão e ampliar um pouco mais para além das tecnologias, dos cabos de fibras óticas. Será que a vontade de estar sempre conectado, nos tempos atuais, on-line, é uma inquietação da sociedade contemporânea, ou a vontade de conexão faz parte da matriz arquetípica do ser humano?

Conexão é o ato ou efeito de conectar, de ligar; ligação, união. É aquilo que liga, une, conecta; conector, junta. Em uma das definições do dicionário Houaiss da língua portuguesa, conexão é um tipo de ligação provisória feita entre duas máquinas para funcionamento combinado simultâneo ${ }^{8}$. De acordo com Bruno Latour", o termo "conexão" tem o mesmo sentido de social, de associação. O intuito é não restringir o social aos humanos, mas ampliar a esfera do social, as coisas, animais, plantas, máquinas tecnológicas etc. Todos esses elementos podem associar-se, conectar-se, desassociar-se e desconectar-se. Por esse motivo, Latour define o social como um movimento peculiar de reassociação e reagregação, tipo de associação momentânea caracterizada pelo modo como se aglutina assumindo novas formas. A sociedade é um coletivo de conexões que fazem e se desfazem. Os atores sociais são os humanos; os não humanos (coisas, objetos, animais, plantas, som, luz) também correspondem aos mediadores em fluxo, em deslocamento, em transformação e movimentação constante. É nesse fluxo que o social é formado, composto por variados mediadores que se conectam e desconectam.

Ao partir do pressuposto teórico de Latour ${ }^{10}$, as palavras "social" e "conexão” possuem o mesmo significado. Algo que é sociável é também conectável, e tem capacidade de associar-se. Fala-se aqui de dois tipos de conexão: aquela explicada por Latour, forma de associação momentânea entre atores sociais que não são necessariamente aparelhos tecnológicos; e a outra traz consigo como suporte a mediação tecnológica para conectar-se. É possível afirmar que as conexões tecnológicas são apenas um grupo dentro das inúmeras possibilidades de conexão. A necessidade de conexão é uma potência afetiva do ser humano. Os indivíduos precisam associar-se, relacionar-se, reconhecer-se no outro. Aí reside a potência humana da conexão: a vontade de comunicar e por consequência simbolizar, para a partir daí construir cultura.

Nos tempos atuais boa parte das conexões entre os humanos é mediada pela tecnologia; os não humanos também se conectam com os humanos. O cenário pode ter mudado um pouco, porém as conexões sempre existiram e sempre vão existir. São essas conexões que formam a sociedade composta de humanos e não humanos. Os conjuntos das conexões formam a rede.

Ao discutir sobre os significados e sentidos da conexão, é possível depreender que a sociedade em rede ou conectada sempre esteve em rede e sempre foi conectada, até porque para existir sociedade é preciso que exista associação, conexão entre seus membros componentes. É claro que Manuel Castells ${ }^{11}$ ao
8. HOUAISS, Antonio; VILLAR, Mauro de Salles. Dicionário Houaiss da língua portuguesa. Rio de Janeiro: Objetiva, 2001.9. LATOUR, Bruno. Reagregando o social: uma introdução à teoria do ator-rede. Salvador: Edufba; Bauru: Edusc, 2012.

10. Ibidem

11. CASTELLS, Manuel. A sociedade em rede Trad. Roneide Venâncio Majer. 4. ed. São Paulo: Paz e Terra, 1999. 
12. FLUSSER, op. cit. 2014, p. 276.

13. FLUSSER, op. cit., 2014. 14. LATOUR, op. cit., 2012.

15. ABED. Censo ead. br: relatório analítico da aprendizagem a distância no Brasil. São Paulo: Pearson Education do Brasil, 2012. Disponível em: http:// www.abed.org.br/censoead/censoEAD.BR 2012_pt.pdf. Acesso em: 31 maio 2019

16. ABED. Censo ear. br: relatório analítico da aprendizagem a distância no Brasil 2014. Curitiba: Ibex, 2015. Disponível em: http://www.abed. org.br/censoead2014/ CensoEAD2014_portugues.pdf. Acesso em: 31 maio 2019.

17. LITTO, Frederic Micael et al. Censo EAD Brasil 2016: relatório analítico de aprendizagem a distância no Brasil. [s.l: s.n.].

18. ABED. Censo ead.br 2017: relatório analítico da aprendizagem a distância no Brasil. Curitiba: InterSaberes, 2018. Disponível em: http://abed.org.br/ arquivos/CENSO_EAD BR_2018_impresso.pdf. Acesso em: 31 maio 2019. nomear a "sociedade em rede" estava fazendo alusão aos fios, cabos de fibra de óptica que transportam milhares de informações, e deixam todos conectados, inseridos na rede de informação.

Flusser dialoga com Latour ao falar em conectividade.

Está em curso uma conectividade em rede que se espalha como um cérebro ao redor do globo terrestre, sendo que os canais são os nervos, e os nós são as pessoas e os aparelhos: essa rede que repousa sobre a biosfera, como a biosfera sobre a hidrosfera, esse cérebro coletivo que está surgindo, que não conhece nem a geografia, nem a história, pois suprimiu (aufgehoben) em si a geografia e a história. Sua função nada mais é que um cruzamento de competências para secretar novas informações e aumentar a competência total do cérebro. Esse é o modelo da sociedade telemática) $)^{12}$.

Tanto Flusser ${ }^{13}$ como Latour ${ }^{14}$ trazem a ideia de rede para pensar as conexões, as conectividades. Latour atrela a ideia de conexão diretamente ao social e amplia, dessa forma, a visão de social difundida pelas ciências sociais clássicas como algo restrito à dimensão humana. A conexão não seria algo dos tempos atuais, mas uma constante sempre presente em todos os tipos de sociedade, independentemente do tempo. Flusser fala que rede é sinônimo de sociedade, e os sujeitos seriam os nós de uma rede. Ambos navegam na mesma direção. A rede é a sociedade, sempre foi.

Imersos nesse cenário de conexões tecnológicas e redes, não podemos esquecer a função que essas conexões desempenham na sociedade/cultura contemporânea. Esse tipo de conexão contamina várias esferas do sujeito urbano, como as artes, a saúde, a política, os relacionamentos amorosos, a cultura de maneira geral, o trabalho e, claro, a educação. Nesse contexto, a educação a distância é um claro exemplo de como as conexões tecnológicas podem ser utilizadas nessa "sociedade telemática". E com o crescimento desta modalidade de ensino, muitos estudos, referenciais e soluções foram desenvolvidos para possibilitar que essa esfera também fosse atingida.

\section{3. ... GERMINANDO UMA NOVA MODALIDADE DE ENSINO...}

A educação a distância (EAD) é uma modalidade de ensino eficiente e eficaz em contemplar grandes contingentes de pessoas de forma efetiva. O Brasil se encontra numa fase de consolidação da EAD, sobretudo no Ensino Superior, que apresenta um crescimento expressivo e sustentado. Conforme os dados do Ministério da Educação do Brasil (MEC), um em cada cinco novos alunos de graduação ingressa em um curso a distância. Ou seja, quase $20 \%$ dos universitários estudam por meio de aulas na internet e com o apoio de polos presenciais.

Nos últimos censos realizados em 2012 ${ }^{15}, 2014^{16}, 2016^{17}$ e $2017^{18}$ pela Associação Brasileira de Educação a Distância (ABED), pode ser constatado que ocorreram mudanças expressivas na quantidade de alunos matriculados em cursos da modalidade EAD. No último censo, foram 1.320.025 alunos matriculados 
Educar na era digital: considerações sobre tecnologia, conexões e educação a distância

- Thiago Tavares das Neves e Elizama das Chagas Lemos

em cursos totalmente a distância e que são regulamentados, 1.119.031 alunos em cursos semipresenciais, também regulamentados, 3.839 .958 alunos em cursos livres e 1.459.813 alunos em cursos corporativos. A Tabela 1 apresenta o número de instituições participantes e o número de matrículas em cursos na modalidade a distância com o decorrer dos anos.

\section{Tabela 1: Evolução das matrículas em EAD no período de 2009-2017}

\begin{tabular}{|c|c|c|}
\hline Ano & Número de instituições participantes do Censo & Número de matrículas em EAD \\
\hline 2009 & 128 & 528.320 \\
\hline 2010 & 198 & 2.261 .921 \\
\hline 2011 & 181 & 3.589 .373 \\
\hline 2012 & 252 & 5.772 .466 \\
\hline 2014 & 271 & 3.868 .706 \\
\hline 2015 & 339 & 5.048 .912 \\
\hline 2016 & 312 & 3.734 .887 \\
\hline 2017 & 351 & 7.773 .828 \\
\hline
\end{tabular}

Pelos dados expressos na Tabela 1, pode-se observar que ocorreu aumento de $52,5 \%$ nas matrículas da modalidade EAD de 2012 para 2011, entretanto houve diminuição de cerca de 32,98\% em cursos de diversas áreas do conhecimento em comparação com dados de 2014, mesmo levando em consideração que o número de instituições participantes tenha aumentado. Também é importante destacar o crescimento constatado no ano de 2017, com mais de 7 milhões de matrículas. Com base nesses dados, pode-se inferir que a modalidade EAD tem ganhado destaque no Brasil.

A democratização no acesso à educação, resultado também das conexões tecnológicas e da sociedade telemática em que se vive atualmente, é outro tema a ser considerado. Pois é nessa conjuntura que a educação a distância surge como um modelo apropriado para superar os desafios educacionais brasileiros. De acordo com Blois ${ }^{19}$, o Brasil tem como característica ser um espaço democrático de convivência de ofertas de EAD e, dessa forma, propicia o atendimento aos excluídos, realizando seu papel de escola para muitos indivíduos, com cursos sendo ofertados tanto em instituições públicas quanto privadas.

O MEC também criou referenciais de qualidade, que envolvem concepção de educação e currículo no processo de ensino e aprendizagem, sistemas de comunicação, material didático, avaliação, equipe multidisciplinar, infraestrutura de apoio, gestão acadêmico-administrativa e sustentabilidade financeira.

Sobre a concepção de educação e currículo no processo de ensino e aprendizagem, os referenciais irão tratar da maneira como o projeto político e pedagógico da instituição é formado, proporcionando uma opção clara de educação, currículo, ensino, aprendizagem e do perfil do aluno que será formado. Os sistemas de comunicação versam sobre o acesso às tecnologias de informação

19 BLOIS, Marlene. Do ensino por correspondência à internet: a busca da democratização do conhecimento. CREAD, v. 8, p. 29-38, 2000. 
e comunicação, proporcionando um efetivo intercâmbio no processo de ensino e aprendizagem, englobando diferentes culturas e diferentes maneiras de construir conhecimento.

O material didático precisa passar por rigorosa avaliação, a fim de que efetivamente possa desenvolver habilidades e competências específicas para o público ao qual é destinado. A equipe multidisciplinar que irá atuar nos cursos EAD também é crucial, e precisa ser estruturada com funções de planejamento, gestão e realização, assim como devem ser constantemente qualificadas para atuar nessa modalidade.

A infraestrutura é requerida e deve ser adequada ao número de alunos da instituição, aos recursos tecnológicos envolvidos e à extensão territorial que os cursos abarcam. Já a gestão acadêmico-administrativa deve estar vinculada aos demais processos da instituição, de forma que um aluno da modalidade a distância tenha o mesmo apoio que outro do ensino presencial, sendo-lhe proporcionados serviços como matrículas, inscrições, requisições, entre outros.

Para que os pontos até então descritos sejam devidamente consolidados, faz-se necessária uma sustentabilidade financeira de forma a custear todo o processo de implantação e oferta de cursos EAD, desde a produção de material didático, compra de equipamentos e capacitação de profissionais. Já para a avaliação são apresentadas duas propostas: a avaliação da aprendizagem (destinada aos discentes) e a avaliação institucional (destinada à equipe docente, técnica e administrativa). Ambas as avaliações são com o objetivo de poder sempre aperfeiçoar a oferta da instituição.

Portanto, a combinação entre tecnologia e educação a distância, associada a interação e compartilhamento de conhecimento, pode proporcionar um ambiente estimulante para o aprendizado e melhorar significativamente o desempenho do aluno e o desenvolvimento de um curso a distância. Curso esse que, para ser efetivado, encontra suporte nessa cultura feita principalmente por conexões tecnológicas, e para que haja maior adequação nesse contexto de educação e novas tecnologias nada mais plausível do que um ambiente virtual de aprendizagem (AVA). Nesse espaço virtual diferentes formas de aprendizado formam outras redes, unindo os nós educação-tecnologia-aprendizado.

\section{4. ... E AMBIENTES DIFERENCIADOS DE APRENDIZAGEM...}

O aumento do uso das tecnologias digitais de informação e comunicação (TDIC) está criando novos ambientes de interação e aprendizagem. Qualquer pessoa em qualquer lugar, desde que tenha uma conexão de internet, pode não somente trocar informações, mas também reconstruir significados, articular ideias tanto de forma individual quanto coletiva. Nesse contexto, conexões entre humanos e não humanos são estabelecidas. A equipe multidisciplinar, professores, tutores, alunos e máquinas (ambientes virtuais de aprendizagem e objetos de aprendizagem, por exemplo) interagem de forma a possibilitar a 
partilha de novos conhecimentos com todos os usuários pertencentes a sua rede. Prova disso é a crescente utilização das redes sociais, que estão modificando a maneira como as pessoas se comunicam.

Petters $^{20}$ fala sobre a importância de se reivindicar uma didática de EAD, transportando a discussão do viés tecnológico para o pedagógico. $\mathrm{O}$ intuito dessa discussão é recuperar e valorizar o histórico da modalidade, de modo que não seja explorado, ou até mesmo negada, trazendo consequências desfavoráveis por desenvolvedores de projetos de $\mathrm{EAD}$, como a repetição de práticas já consolidadas ou obsoletas. Logo, a equipe multidisciplinar que tem voz ativa no processo de aprendizagem precisa estar bem articulada também nesses aspectos.

O conceito de conectivismo se encaixa de forma adequada nesse processo de troca na era digital. Pois, entre seus princípios, é importante frisar que aprendizagem e conhecimento são apoiados na diversidade de opiniões entre os atores participantes. Além disso, a aprendizagem é percebida como um processo de conectar nós enquanto fontes de informação, e ela pode residir em dispositivos não humanos. Isso leva a outro princípio importante de multidisciplinaridade do processo de construção de conhecimento, que trabalha a habilidade de enxergar conexões entre áreas, ideias e conceitos como uma tendência fundamental e necessária ${ }^{21}$. Tais princípios desta teoria se articulam muito bem com a modalidade a distância.

Pois, na EAD, não podemos utilizar a clássica concepção de sala de aula, com alunos como meros expectadores enfileirados diante de um professor especialista detentor de todo o conhecimento. Na educação a distância necessitamos de um ambiente focado na interação entre alunos e professores. Outro princípio de Siemens que se articula muito bem com essas ideias é o da necessidade de cultivar e manter conexões para facilitar a aprendizagem contínua.

Afinal, é necessário focar na concepção de ambientes com uma abordagem construcionista, que favoreçam a coconstrução do conhecimento, o alcance da consciência ética e crítica decorrente de diálogo e interação. Isso significa uma nova concepção de ambiente de aprendizagem - comunidade de aprendizagem, ou seja, uma comunidade de aprendizagem que se estabeleça na forma de ambientes virtuais de aprendizagem (AVA $)^{22}$.

Ainda estabelecendo um diálogo com o conectivismo, a gestão do conhecimento se encaixa muito bem na troca dos atores nesses ambientes virtuais. Pois a teoria também aborda as mudanças que muitas instituições encontram nas atividades de gestão do conhecimento. Assim, o conhecimento é armazenado em uma base de dados e precisa ser vinculado com as pessoas e contextos certos para que possa ser classificado como aprendizagem. Portanto, para a modalidade EAD, o trabalho com esses ambientes virtuais para a gestão do conhecimento, o espaço para armazenamento e interação entre os atores neste processo educacional, é perspectiva importante a ser considerada.

E para romper com o modelo tradicional de educação supracitado, a tecnologia e as conexões em redes digitais são importantes aliados nesse processo. Ainda em se tratando de EAD, os AVA são instrumentos indissociáveis para
20. PETERS, Otto. Didática do ensino a distância: experiências e estágio da discussão numa visão internacional. Trad. Ilson Kayser. São Leopoldo: Editora Unisinos, 2001.

21. SIEMENS, George Connectivism: a learning theory for the digital age. International Journal of Instructional Technology and Distance Learning, v. 2, n. 1, jan. 2005. Traduzido para o português e disponível em: http:// usuarios.upf.br/ teixeira/ livros/conectivismo\%5Bsiemens\%5D.pdf. Acesso em: 14 out. 2020.

22. HENRIQUE, Ana Lúcia Sarmento et al. Curso de aperfeiçoamento para professores dos municípios do RN: Módulo I: Informática; Módulo II: Língua Portuguesa; Módulo III: Ética e Cidadania para um Trabalho Transdisciplinar; Módulo IV: Educação Matemática. Natal: IFRN, 2011. 
propiciar o processo de construção de conhecimento por meio desta modalidade. Segundo Behar ${ }^{23}$, um ambiente virtual de aprendizagem pode ser definido como um espaço na internet formado pelos sujeitos, suas interações e formas de conexão que se estabelecem por meio de uma plataforma, tendo como foco principal a aprendizagem. Nesse contexto, uma plataforma pode ser definida como uma infraestrutura tecnológica composta pelas funcionalidades e interface gráfica que compõem o $\mathrm{AVA}^{24}$.

Os AVA apresentam os mais variados recursos, como disponibilizar um simples documento para os alunos e até mesmo elementos mais sofisticados, como um sistema de questionários on-line. Proporcionam condições para a interação síncrona ou assíncrona, permanente, entre seus usuários, pois são baseados na conectividade. Isso garante o acesso rápido à informação e à comunicação interpessoal, em qualquer tempo e lugar, amparando o desenvolvimento de projetos em colaboração e a coordenação das atividades.

Segundo Tori ${ }^{25}$, os principais recursos dos AVA são: gerenciamento dos cursos, gerenciamento de conteúdo, disco virtual, correio eletrônico, mensagem instantânea, salas de bate-papo, lousa virtual, compartilhamento de recursos, avaliação e área de apresentação do aluno.

Atualmente existem muitos AVAs disponíveis, com os mais variados custos, formas de licenciamento, funcionalidades e recursos. Alguns são softwares livres, como o Moodle; outros são pagos, como o Blackboard. Existem também alguns ambientes desenvolvidos no Brasil que são de boa qualidade e de livre acesso: o Teleduc, desenvolvido na Universidade Estadual de Campinas; o AulaNet, desenvolvido na Pontifícia Universidade Católica do Rio de Janeiro; e o Openredu, desenvolvido por estudantes do Centro de Informática da UFPE (Universidade Federal de Pernambuco). Mais uma vez a tecnologia atua como peça fundamental, pois além dos AVA existem outros elementos que possibilitam a partilha e facilitam as conexões entre professor e aluno em um ambiente interativo, como os objetos de aprendizagem.

23. BEHAR, Patricia Alejandra. Modelos pedagógicos em educação a distância. Porto Alegre: Artmed, 2009.

24. Ibidem

25. TORI, Romero. Educação sem distância: as tecnologias interativas na redução de distâncias em ensino e aprendizagem. São Paulo: Editora Senac São Paulo, 2010.

\section{5. ... QUE UTILIZAM OUTROS OBJETOS COMO FERRAMENTAS EDUCATIVAS...}

Aprender é um processo de criação intrinsecamente ligado a transformação. E para que haja aprendizado nesse cenário virtual, é imprescindível o uso da tecnologia e das conexões que se formam entre os alunos e os dispositivos digitais. A conexão, nesse caso, a virtual (tecnológica), passa ser basilar para a construção do conhecimento interativo. O processo de aprendizagem se constrói primeiramente na rede que se tece nas conexões interativas entre professor, aluno e máquina (dispositivo tecnológico). As tecnologias de informação e comunicação estão cada vez mais presentes em sala de aula, ampliando as possibilidades de transmissão dos conhecimentos e o repertório do professor na sala de aula, seja ela virtual ou presencial. No entanto, é necessário que haja uma devida 
relação entre os processos de ensino e a aprendizagem, a fim de se ter o devido cuidado em relação à proposta de ensino, ao modo como os materiais educativos são projetados e utilizados e como o conhecimento é gerado e construído.

Um exemplo desse tipo de material que faz uso das TDIC são os objetos de aprendizagem (OA). Também podem ser chamados de conteúdos didáticos digitais e entendidos como qualquer entidade que possa ser utilizada, reutilizada ou referenciada durante o aprendizado apoiado pelo uso das tecnologias ${ }^{26}$. Exemplos desse tipo de tecnologia são os sistemas de treinamento, sistemas inteligentes de instrução auxiliadas por computador e os ambientes de aprendizagem colaborativa.

A partir da definição proposta por Wiley, L'Allier $^{27}$ ainda propõe uma abordagem definindo OA como uma experiência instrucional independente que contém um objetivo, uma atividade de aprendizagem e uma avaliação. $\mathrm{O}$ autor criou um modelo denominado de componente estrutural do OA.

Segundo esse modelo, cada elemento tem uma definição específica. O objetivo é um elemento que descreve o resultado esperado com base em critérios que se destinam a uma atividade de aprendizagem. Esta atividade se apresenta como um elemento de um componente estrutural de OA que ensina um objetivo. Já a avaliação mostra um elemento que determina o grau de concretização desse objetivo.

Os objetos de aprendizagem usam como referência o paradigma de programação orientada a objetos, das ciências da computação. A orientação a objetos pode ser entendida como um paradigma de análise, projeto e programação de sistemas baseado na composição e interação entre diversas unidades de software, chamadas de objetos, que são capazes de ser reutilizadas em diferentes contextos ${ }^{28}$.

Por meio desse paradigma, os OA oferecem atributos que buscam solucionar diversos problemas existentes em relação a armazenamento e distribuição de informação por meios digitais, como, por exemplo, flexibilidade, facilidade para atualização, customização, interoperabilidade - cooperação e colaboração -, aumento de valor do conhecimento, indexação e procura.

A customização é uma característica-chave dos OA. Como os objetos podem ser empregados em várias situações, sua atualização se torna relativamente simples desde que todas as informações relativas ao objeto estejam reunidas num mesmo banco de informações. Já a interoperabilidade trata dessa troca entre professor e aluno, possibilitando uma aprendizagem mútua por parte dos dois polos do saber.

Os OA abrangem conteúdos multimídia, conteúdo instrucional, softwares educativos e ferramentas de software, bem como as pessoas, organizações e eventos referenciados pela tecnologia. Sendo bem aproveitados, podem enriquecer o repertório do professor em sala de aula, seja ela presencial ou a distância. O docente pode, por exemplo, utilizar OA para elucidar de forma mais prática um conceito, fazer exercícios, simular um fenômeno físico, entre outras possibilidades.
26. WILEY, David. Connecting learning objects to instructional design theory: a definition, a metaphor, and a taxonomy. [s.d.] Disponível em: http:// wesrac.usc.edu/wired/ bldg-7_file/wiley.pdf. Acesso em: 11 abr. 2014; IEEE. The learning object metadata standard. [s.d.] Disponível em: http:// Itsc.ieee.org/wg12/files/. Acesso em: 21 nov. 2011.

27. L'ALLIER. NETg's map to its products, their structures and core beliefs. 1997. Disponível em: http://web.archive.org/ web/20020615192443/ www.netg.com/research/ whitepapers/frameref.asp. Acesso em: 18 out. 2013.

28. DALL'OGLIO, Pablo. PHP: programando com orientação a objetos. 2. ed. São Paulo: 2009. 
Todavia, o trabalho de construção de um OA não ocorre de forma separada, porque abarca conhecimentos distintos que muitas vezes o professor não tem. Então, se faz necessária a intervenção de três equipes: a pedagógica, a tecnológica e a de design. A equipe pedagógica começa o processo de concepção e é responsável por selecionar os conteúdos abordados e a maneira como eles serão tratados. As ideias desenvolvidas pela equipe pedagógica são estruturadas em um roteiro para que o OA possa ser implementado pela equipe de design e tecnológica.

Vale mencionar que existem outros modelos também difundidos para desenvolvimento de materiais didáticos. O modelo CDWT (conteudista + designer instrucional + webdesigner + tutor), por exemplo, determina que o processo de planejamento de um curso a distância começa com um conteudista, que elabora o conteúdo que é posteriormente trabalhado por um designer instrucional e um webdesigner. Após esse processo de elaboração, é disponibilizado para o aluno, que conta com o atendimento de um tutor ${ }^{29}$.

Após o desenvolvimento, esses OA devem ser armazenados de forma adequada em sistemas de gestão de conteúdos de aprendizagem (do inglês learning content management systems, LCMS), a fim de que o usuário possa localizar, escolher, organizar e apresentar os conhecimentos de forma arranjada nessas bases. Existem várias iniciativas baseadas na utilização de $\mathrm{OA}$, onde são criados repositórios para consulta e utilização. Dentre eles enfatizam-se o Projeto RIVED $^{30}$ - Rede Interativa Virtual de Educação - e o Banco Internacional de Objetos Educacionais ${ }^{31}$.

Os OA podem ser instrumentos bastante eficazes de construção de conhecimento para o aluno e para o professor. Uma vez bem utilizados, possibilitam ampliar as formas de interação entre os participantes e otimizar a compreensão e partilha de conhecimento.

29. MATTAR, João. Conteudista + designer instrucional + webdesigner + tutor = uma equação que não fecha. In: BARROS, D. M. V. et al. Educação e tecnologias: reflexão, inovação e práticas. Lisboa: 2011.

30. Disponível em: http:// rived.mec.gov.br/. Acesso em: 25 ago. 2013.

31. Disponível em: http://objetoseducacionais2.mec.gov.br/. Acesso em: 25 ago. 2013

\section{6. ... FOMENTANDO NOVOS OLHARES SOBRE O EDUCAR NA SOCIEDADE TECNOLÓGICA.}

E foi com o objetivo de problematizar a técnica, a tecnologia e as conexões que este texto tentou refletir sobre a relevância desses três tópicos na construção de uma aposta de aprendizado diferenciado, a educação a distância. Sua principal diferença reside no suporte (dispositivos digitais) e nas conexões tecnológicas que possibilitam a mediação. É nesse contexto que a EAD entra como uma modalidade de ensino com diversos recursos digitais e interativos (ambientes virtuais de aprendizagem e objetos de aprendizagem), contribuindo, dessa forma, com outros olhares no processo educativo da sociedade telemática. 


\section{REFERÊNCIAS BIBLIOGRÁFICAS}

ABED. Censo ead.br: relatório analítico da aprendizagem a distância no Brasil. São Paulo: Pearson Education do Brasil, 2012. Disponível em: http://www.abed.org.br/censoead/censoEAD.BR_2012_pt.pdf. Acesso em: 31 maio 2019.

ABED. Censo ear.br: relatório analítico da aprendizagem a distância no Brasil 2014. Curitiba: Ibex, 2015. Disponível em: http://www.abed.org.br/ censoead2014/CensoEAD2014_portugues.pdf. Acesso em: 31 maio 2019.

ABED. Censo ead.br 2017: relatório analítico da aprendizagem a distância no Brasil. Curitiba: InterSaberes, 2018. Disponível em: http://abed.org.br/ arquivos/CENSO_EAD_BR_2018_impresso.pdf. Acesso em: 31 maio 2019.

BARFIELD, Thomas (ed.). Diccionario de antropologia. Barcelona: Bellaterra, 2001.

BEHAR, Patricia Alejandra. Modelos pedagógicos em educação a distância. Porto Alegre: Artmed, 2009.

BLOIS, Marlene. Do ensino por correspondência à internet: a busca da democratização do conhecimento. CREAD, v. 8, p. 29-38, 2000.

CASTELLS, Manuel. A sociedade em rede. Trad. Roneide Venâncio Majer. 4. ed. São Paulo: Paz e Terra, 1999.

DALL'OGLIO, Pablo. PHP: programando com orientação a objetos. 2. ed. São Paulo: 2009.

FLUSSER, Vilém. Comunicologia: reflexões sobre o futuro. São Paulo: Martins Fontes, 2014.

FLUSSER, Vilém. O mundo codificado: por uma filosofia do design e da comunicação. São Paulo: Cosac Naify, 2007.

HENRIQUE, Ana Lúcia Sarmento et al. Curso de aperfeiçoamento para professores dos municípios do RN: Módulo I: Informática; Módulo II: Língua Portuguesa; Módulo III: Ética e Cidadania para um Trabalho Transdisciplinar; Módulo IV: Educação Matemática. Natal: IFRN, 2011.

HOUAISS, Antonio; VILLAR, Mauro de Salles. Dicionário Houaiss da língua portuguesa. Rio de Janeiro: Objetiva, 2001.

IEEE. The learning object metadata standard. [s.d.] Disponível em: http://ltsc.ieee.org/wg12/files/. Acesso em: 21 nov. 2011.

L'ALLIER. NETg's map to its products, their structures and core beliefs. 1997. Disponível em: http://web.archive.org/web/20020615192443/www.netg. com/research/whitepapers/frameref.asp. Acesso em: 18 out. 2013. 
LATOUR, Bruno. Reagregando o social: uma introdução à teoria do ator-rede. Salvador: Edufba; Bauru: Edusc, 2012.

LITTO, Frederic Micael et al. Censo EAD Brasil 2016: relatório analítico de aprendizagem a distância no Brasil. [s.l: s.n.].

MATTAR, João. Conteudista + designer instrucional + webdesigner + tutor = uma equação que não fecha. In: BARROS, D. M. V. et al. Educação e tecnologias: reflexão, inovação e práticas. Lisboa: 2011.

MCLUHAN, Marshall. Os meios de comunicação como extensões do homem. São Paulo: Cultrix, 2007.

PARÍS, Carlos. O animal cultural: biologia e cultura na realidade humana. São Carlos: EdUFSCar, 2002.

PETERS, Otto. Didática do ensino a distância: experiências e estágio da discussão numa visão internacional. Trad. Ilson Kayser. São Leopoldo: Editora Unisinos, 2001.

SIEMENS, George. Connectivism: a learning theory for the digital age. International Journal of Instructional Technology and Distance Learning, v. 2, n. 1, jan. 2005. Traduzido para o português e disponível em: http://usuarios.upf.br/ teixeira/livros/conectivismo\% 5 Bsiemens $\% 5 \mathrm{D}$. pdf. Acesso em: 14 out. 2020.

TORI, Romero. Educação sem distância: as tecnologias interativas na redução de distâncias em ensino e aprendizagem. São Paulo: Editora Senac São Paulo, 2010.

TURKLE, Sherry. Alone together: why we expect more from technology and less from each other. Nova York: Basic Books, 2011.

WILEY, David. Connecting learning objects to instructional design theory: a definition, a metaphor, and a taxonomy. [s.d.] Disponível em: http://wesrac. usc.edu/wired/bldg-7_file/wiley.pdf. Acesso em: 11 abr. 2014. 